\title{
Afyonkarahisar İli Çevresinde Yetișen ve Halk Tarafından Tüketilen Bazı Yabani Bitkilerin Antioksidan ve Antimikrobiyal Etkileri
}

\author{
Gökhan Akarca ${ }^{1 *}$, Oktay Tomar ${ }^{2}$ \\ ${ }^{1}$ Afyon Kocatepe Üniversitesi, Mühendislik Fakültesi, Gıda Mühendisliği Bölümü, Afyonkarahisar, Türkiye (ORCID: 0000-0002-5055-2722) \\ ${ }^{2}$ Afyon Kocatepe Üniversitesi, Mühendislik Fakültesi, Gıda Mühendisliği Bölümü, Afyonkarahisar, Türkiye (ORCID: 0000-0001-5761-7157)
}

(İlk Geliş Tarihi 26 Aralık 2018 ve Kabul Tarihi 16 Şubat 2019)

(DOI: 10.31590/ejosat.502709)

ATIF/REFERENCE: Akarca, G. \& Tomar, O. (2019). Afyonkarahisar İli Çevresinde Yetişen ve Halk Tarafindan Tüketilen Bazı Yabani Bitkilerin Antioksidan ve Antimikrobiyal Etkileri. Avrupa Bilim ve Teknoloji Dergisi, (15), 259-267.

$\ddot{O} \mathbf{z}$

Bu çalışmada, Afyonkarahisar ili ve çevresinde yaşayan halk tarafından gıda olarak tüketilen acıgünek, bici bici, sığı̆r kuyruğu ve ekşimenin antioksidan ve antimikrobiyal özelliklerinin belirlenmesi amaçlanmıştır. Araş̧ırma sonucunda DPPH Serbest Radikal Giderme Aktivitesi (\%) ve Toplam fenolik madde miktarı en fazla \% $52.46 \pm 1.25$ ve $0.55 \pm 0.60 \mathrm{GAE}$ mM değer ile ekşimende

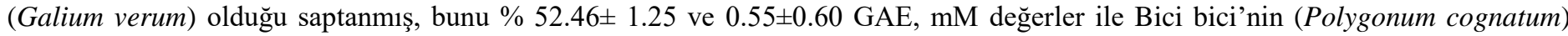
takip ettiği belirlenmiştir. Yapılan antimikrobiyal aktivite testleri sonucunda ise; en fazla antimikrobiyal etkinin yine ekşimen tarafından gösterildiği, Escherichia coli'ye karş1 $28 \pm 0.02$ ve Listeria monocytogenes'e karş̧ $26 \pm 0.00 \mathrm{~mm}$ zon çapı oluşturduğu tespit edilmiştir. Ekşimenin bu bakteriler üzerindeki MIC ve MBC değerleri ise sırasıyla; 24 ve $48 \mu \mathrm{g} / \mathrm{mL}$ olarak belirlenmiştir.

\section{Antioxidant and Antimicrobial Effects of Some Wild Plants Growing Around Afyonkarahisar Province and Consumed by People}

\begin{abstract}
In this study, it is aimed to determine the antioxidant and antimicrobial properties of dandelion, Polygonum, mullein and dock consumed by people living in Afyonkarahisar province. At the end of the study, DPPH Free Radical Removal Activity (\%) and Total phenolic content of dock (Galium verum L.) were $52.46 \pm 1.25 \%$ and $0.55 \pm 0.60$ GAE mM, respectively, and followed by Polygonum (Polygonum cognatum L.) with \% 52.46 \pm 1.25 and $0.55 \pm 0.60$ GAE mM values. As a result of the antimicrobial activity tests; the dock had an antimicrobial effect with forming a zone diameter of $28 \pm 0.02$ against Escherichia coli and $26 \pm 0.00$ mm against Listeria monocytogenes. The MIC and MBC values of dock of these bacteria were determined as 24 and $48 \mu \mathrm{g} / \mathrm{mL}$, respectively.
\end{abstract}

Keywords: Weed, Antioxidant, Antimicrobial, MIC, MBC.

\footnotetext{
${ }^{1}$ Sorumlu Yazar: Sorumlu Yazar: Afyon Kocatepe Üniversitesi, Mühendislik Fakültesi, Gıda Mühendisliği Bölümü, Afyonkarahisar, Türkiye, ORCID: 0000-0001-5761-7157 gakarca@aku.edu.tr
} 


\section{Giriş}

Türkiye, Dünyada bulunduğu konum itibari ile oldukça zengin bir floraya sahip bir ülke olup yaklaşı 12000 civarında bitki taksonuna ev sahipliği yapmaktadır (Akçiçek ve Vural, 2007). Afyonkarahisar Türkiye'de İç Anadolu, Ege ve Akdeniz bölgelerinin birleştiği noktada yer alan bir ildir. $38^{\circ} 44^{\prime}$ kuzey ve $30^{\circ} 34^{\prime}$ doğu enlem ve boylamları arasında yer alan şehrin denizden yüksekliği $1020 \mathrm{~m}$ dir (Kargığlu, 2001). Denizlere uzak ve etrafı dağlar ile çevrili olduğundan kara iklimi hakimdir (Anonim, 2010).

Türkiye'de halkın beslenmesinde önemli bir yeri olan yabani bitkiler, özellikle kırsal kesimlerde yaşayan halk tarafından tercih edilmektedir. Yabani bitkiler günlük diyetlerde önem arz eden vitamin, mineral ve protein içeriği açısından zengin kaynaklardır (Yücel ve Tunay, 2002) Bu bitkiler aynı zamanda yüksek antimikrobiyal ve antioksidant aktiviteye sahip bileşikler içermektedirler (Da-Costa-Rocha ve ark., 2014).

Afyonkarahisar ili çevresinde yaşayan halk tarafindan da bu türden pek çok bitki gıda amaçlı olarak tüketilmektedir. Acıgünek, bicibici, sığır kuyruğu ve ekşimen bu bitkiler arasında yer almaktadır. Karahindiba (Taraxacum officinale), ya da bölge halkı tarafından bilinen adıyla acıgünek, Asteracea familyasına ait, çayırlarda kendiliğinden yetişen, çok yıllık, $10 \mathrm{~cm}$ boyunda bir bitkidir (You ve ark., 2010). Mart-Ağustos aylarında sarı renkli çiçek açan bitki, ters mızrak şeklinde, üçgen benzeri parlak yeşil yapraklara sahiptir. Yapraklar bitkinin alt kısmında lokalize olmuştur. Yaprakları yöre halkı tarafından toplanıp taze olarak tüketilmektedir (Yücel ve ark., 2012). Bici bici (Polygonum cognatum) Polygonaceae familyasından çok yıllık bir bitki olup çoğunlukla Kuzey ılıman bölgelerinde dünya çapında dağıtılan yaklaşık 300 türden oluşur (Wang ve ark., 2005). Bahar ayında pembe kırmızı renkli çiçekler açan bitkinin yaprakları elips şekilli, kısa saplı ve uçları sivridir. Bitkinin yeşil yaprakları toplanıp temizlendikten sonra taze olarak tüketilmektedir (Yücel ve ark., 2012).

Verbascum lasianthum, sığır kuyruğu Scrophulariaceae familyasından iki yıllık bir bitkidir. Sivri şekilli yapraklara sahip olan bitki, mayıs- eylül aylarında sarı renkli çiçekler açmaktadır (Başer, 2015). Bitkinin yaprakları temizlenip yıkandıktan sonra taze olarak tüketilebildiği gibi çiçekleri ise, çay olarak tüketilebilmektedir (Yücel ve ark., 2012). Galium verum ekşimen Rubiaceae familyasından çok yıllık bir bitkidir. İlkbahar aylarında sarı renkli çiçekler açan bitkinin yaprakları mızrak şekilli, kenarları kıvrık ve pürüzlüdür (Yücel, 2012). Bölge halkı tarafından bitkinin taze yaprakları toplanıp taze olarak tüketilmektedir (Yücel ve ark., 2012).

$\mathrm{Bu}$ çalışmada, Afyonkarahisar ili ve çevresinde yaşayan halk tarafından gıda olarak tüketilen bazı yabani otların (acıgünek, bici bici, sığır kuyruğu ve ekşimen) antioksidant ve antimikrobiyal özelliklerinin belirlenmesi amaçlanmıştır.

\section{Materyal ve Metot}

\subsection{Bitkisel Materyal}

Çalışmada kullanılan bitkiler Nisan- Haziran ayları arasında Afyonkarahisar ili kırsalından elle toplanmıştır.

\subsection{Etanol Ekstrakların Hazırlanması}

Araştırmada kullanılan bitkiler taze halde bir bıçak yardımı ile küçük parçalara ayrıldı ve 100'er gram tartılarak, üzerlerine 400 $\mathrm{ml} \% 80$ 'lik etil alkol ilave edildi. Ardından 24 saat boyunca shaker (WiseShake ${ }^{\circledR}$ SHO-2D) kullanılarak 120 rpm de karıştırıldı. Süre sonunda karışım sterilize $22 \mathrm{~mm}$ filtre kağıdından süzülerek, rotary evaporatöre (Heidolph Hei-VAP value) alınarak $100 \mathrm{rpm}$ devirde ve $60{ }^{\circ} \mathrm{C}$ sicaklıkta alkol ve ekstrak kısmı birbirinden ayrıldı.

\subsection{DPPH Serbest Radikal Giderme Aktivitesi}

Bitki örneklerinin etanol ekstraklarından $0,025 \mathrm{ml}$ alınarak $4 \mathrm{~mL}$ metanolde $(0.0625 \mathrm{mg} / \mathrm{mL})$ çözündürüldü. Daha sonra 0.5 $\mathrm{mL}$ metanolik bir $\alpha, \alpha$-diphenyl- $\beta$-picrylhydrazyl (DPPH) ( $1 \mathrm{mM}$ ) çözeltisi ile karıştırıldı ve oda sicaklı̆̆ında 30 dakika beklemeye bırakıldı. Ardından karışımın optik yoğunluğu spekrofotometre ile (Hitachi U-2000) 517 nm'de ölçüldü (Chu ve Chen, 2006).

Bitki örneklerinin etanol ekstraklarının serbest radikal giderme aktivitesi aşağıdaki denklemle hesaplandı

Süpürme Kapasitesi $(\%)=[1-(\mathrm{As}-\mathrm{Ab}) /(\mathrm{Ac}-\mathrm{Ab})] \cdot 100$

As: Örneklerin Absorbans değeri

Ab: Kör Numune

Ac: Kontrol Numunesi

\subsection{Toplam Fenolik Madde Miktarının Belirlenmesi}

Bitki örneklerinden ektraktlarından $0.05 \mathrm{ml}$ ' alınarak üzerine $2 \mathrm{ml} \%$ 2'lik sodyum karbonat eklenmiştir. 2 dakika beklendikten sonra sonra, yukarıdaki çözelti ile $0.1 \mathrm{ml}$ Folin-Ciocalteu reaktifi karıştırıldı, $30 \mathrm{dk}$ beklenildikten sonra spekrofotometre ile (Hitachi 
U-2000) 750 nm'de absorbans ölçüldü. Toplam fenolik madde içeriği, kalibrasyon eğrisinden gallik asit eşdeğerleri (GAE, mM) olarak ifade edildi (Chu ve Chen, 2006).

\subsection{Kullanılan Suşlar}

Araştırmada; Esherichia coli ATCC 25922, Listeria monocytogenes ATCC 51774, Staphylococcus aureus ATCC 6538, Pseudomonas aeroginosa ATCC 10145, Enterococcus faecalis ATCC 51299 ve Salmonella Typhi ATCC 6539 bakterileri kullanıldı. Bakteri suşları kanlı agarda 4-7 ${ }^{\circ} \mathrm{C}^{\prime}$ de muhafaza edildi ve $35 \pm 0.1{ }^{\circ} \mathrm{C}$ 'de 24 saat Mueller-Hinton Broth (Merch 110293 ) kültüre alınd1.

\subsection{Disklerinin Hazırlanması}

Çıkartılan bitki ekstraktlarlardan $10 \mu \mathrm{L}$ steril petri kutuları içerisine alınarak ve üzerine boş antibiyotik diskleri (Bio-Disk 316010001) yerleştirildi. Disklerin ekstrakları emmesi için petri kutuları kapakları kapalı şekilde 1 saat boyunca buzdolabında (4 ${ }^{\circ} \mathrm{C}$ 'de) bekletildi.

\subsection{Disk Difüzyon Yöntemiyle Antimikrobiyal Aktivitenin Belirlenmesi}

Muller Hinton broth 'da bulunan her bakteri suşundan $0.1 \mathrm{ml}\left(10^{6}-10^{7} \mathrm{CFU} / \mathrm{ml}\right)$ numune alınarak Muller Hinton Agar (Merck 1,05437) (MHA) yüzeyine cam drigalski spatulü yardımıyla, inokulasyon besiyeri tarafından tamamen emilene kadar homojen bir şekilde yayıldı. Besiyerinin inokülasyonu emmesi için 10 dakika bekledikten sonra, $10 \mu \mathrm{L}$ ekstrakt emdirilmiş diskler (Bio-Disk 316010001 ) petri agar yüzeyine yerleştirildi (Cruz-Gálvez ve ark., 2018).

Daha sonra petri kutuları (90 mm., Firatmed, Türkiye), Antimikrobiyal Duyarlılık Testleri Avrupa Komitesi'nde belirtilen şartlar altında (16-20 saatte $35^{\circ} \mathrm{C}$, Listeria monocytogenes $\% 5 \mathrm{CO}_{2}$, diğer tüm bakteriler aerobik) inkübasyona bırakıldı (Eucast, 2018). İnkübasyon periyodunun sonunda oluşan bölgeler, uygun bir ışı altında dijital bir kumpas yardımıyla ölçüldü.

\subsection{Minimum Inhibitory Concentration (MIC) Derecesinin ve Minimum Bactericidal Concentration (MBC) Belirlenmesi}

Araştırmada kullanılan dört bitkinin etanol ekstratlarının, 8 farklı gıda kaynaklı patojen bakteri üzerindeki MIC değerlerinin belirlenmesinde bifold dilüsyon yöntemi kullanıldı. Her bir bitki ekstraktı için ayrı ayrı olacak şekilde, beş adet steril tüp içerisine 2 şer $\mathrm{ml}$ nutrient broth (Merck 1.05443) ve bir tüp içerisine de $4 \mathrm{ml}$ bitki ekstraktı ilave edildi. Bitki ekstraktı bulunan tüpten 2 ml alınarak, içerisinde $2 \mathrm{ml}$ nutrient broth bulunan tüp içerisine ilave edildi. Homojen bir şekilde vortex de (IKA MS-3, Almanya) karıştırıldıktan sonra, bu tüpten $2 \mathrm{ml}$ besiyeri ve ekstrakt karışımında alındı ve üçüncü tüpe aktarıldı işleme bu şekilde son tüpe kadar devam edildi. Son olarak 5 numaralı tüpten de $2 \mathrm{~mL}$ ekstrakt ve besiyeri karışımından alınarak atıldı. Böylece her tüpte eşit miktarda ancak bir öncekine göre yarı yarıya azalmış konsantrasyonlar elde edildi. Tüplerin son konsantrasyonları 800, 400, 200, 100, 50, ve 25 $\mathrm{mg} / \mathrm{L}$. olacak şekilde oluşturuldu. Ayrıca içerisinde sadece $2 \mathrm{ml}$ nutrient broth bulunan pozitif kontrol ile $2 \mathrm{ml}$ ekstrakt ve $2 \mathrm{~mL}$ Nutrient broth karışımı bulunan negatif kontrol tüpleri de oluşturdu. Negatif kontrol hariç diğer tüm tüpler içerisine $1 \mu \mathrm{l}\left(10^{6} \mathrm{kob} / \mathrm{ml}\right.$

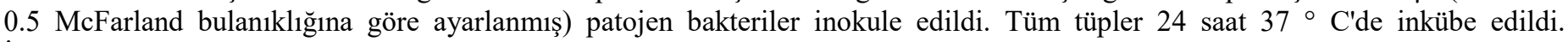
İnkübasyondan sonra, gözle görünür herhangi bir mikrobiyal gelişme göstermeyen tüpün konsantrasyonu MIC değeri olarak kabul edildi (El Mahmood, 2009; By Aamer ve ark., 2015; Chikezie, 2017).

Esherichia coli, Listeria monocytogenes, Staphylococcus aureus, Pseudomonas aeroginosa, Enterococcus faecalis, Salmonella Typhi ve Bacillus subtilis'e karşı araştırmada kullanılan bitki ekstraklarının MBC değerlerinin belirlenmesi için; herhangi bir mikrobiyal gelişme görülmeyen MIC tüplerinin her birinden $1 \mu \mathrm{l}$ alınarak Mueller-Hinton agar yüzeyine yayma plak yöntemi kullanılarak ekim yapıldı. 24 saat $37^{\circ}$ C'de inkübasyonun ardından gelişme göstermeyen en düşük konsantrasyon, test edilen bakteri türüne karşı kullanılan bitki ekstraktının MBC değeri olarak tespit edildi (Dhiman, ve ark., 2011; By Aamer, ve ark., 2015; Chikezie, 2017).

\section{Araştırma Sonuçları ve Tartışma}

\subsection{DPPH Serbest Radikal Giderme Aktivitesi}

Afyonkarahisar il kırsalından toplanan bitkilerden elde edilen etanol ekstraktlarının DPPH radikal giderme aktivite analiz sonuçları Tablo 1 de gösterilmiştir.

Tablo 1. Bitki Ekstraklarının DPPH Sertbest Radikal Giderme Aktivite Dĕ̌gerleri

\begin{tabular}{lcc}
\hline Bitki & $\begin{array}{c}\text { DPPH Serbest Radikal } \\
\text { Giderme Aktivitesi (\%) }\end{array}$ & $\begin{array}{c}\text { Toplam Fenolik Madde } \\
\text { (GAE, mM) }\end{array}$ \\
\hline Acıgünek (Taraxacum officinale) & $41.20 \pm 1.05$ & $0.47 \pm 0.28$ \\
Bicibici (Polygonum cognatum) & $52.46 \pm 1.25$ & $0.55 \pm 0.60$ \\
Sığır Kuyruğu (Verbascum lasianthum) & $51.36 \pm 0.24$ & $0.32 \pm 0.91$ \\
Ekşimen (Galium verum) & $61.4 \pm 0.94$ & $0.85 \pm 0.36$ \\
\hline
\end{tabular}




\section{Avrupa Bilim ve Teknoloji Dergisi}

Araştırmada kullanılan tüm bitkilerin iyi bir antioksidan aktiviteye sahip olduğu ortaya konulmuştur. En yüksek antioksidan aktivitesine \%61,4 ile Ekşimenin (Galium verum), en az antioksidan aktivitesine ise; \%41,20 ile Acıgüneğin (Taraxacum officinale) sahip olduğu belirlenmiştir (Tablo1).

Bokhari ve ark. (2013), altı farklı çözücü kullanarak elde ettikleri Galium aparine ekstraklarında en yüksek antioksidan aktivitesine, $\% 58,3 \pm 1.32$ ile saf su ekstraktından elde ettiklerini belirtmişlerdir.

Ekşimenin (Galium verum L.), bileşiminde p-Kumarik asit $(0.983 \pm 0.10 \mathrm{mg} / 100 \mathrm{~g})$, Izokuersitrin $(78.021 \pm 0.95 \mathrm{mg} / 100 \mathrm{~g})$, Rutin $(804.262 \pm 1.89 \mathrm{mg} / 100 \mathrm{~g})$, kuersitrin $(23.64 \pm 0.13 \mathrm{mg} / 100 \mathrm{~g})$, Quersetin $(26.80 \pm 0.15 \mathrm{mg} / 100 \mathrm{~g})$ ve Kaempferol $(3.069 \pm 0.17 \mathrm{mg} / 100 \mathrm{~g})$ bulunduğunu, bitkinin yüksek antioksidan aktivitesinin bu bileşiklerden kaynaklanabileceğini belirtmişlerdir (Vlase ve ark., 2014).

\subsection{Toplam Fenolik Madde Miktarının Belirlenmesi}

Dört farklı bitkinin etanol ekstraklarının toplam fenolik madde miktarları tablo 1 de gösterilmiştir. Toplam fenolik madde miktarı en yüksek örnek $0.85 \pm 0.36 \mathrm{GAE}, \mathrm{mM}$ ile, ekşimen örneğine ait olduğu, bunu $0.55 \pm 0.60 \mathrm{GAE}, \mathrm{mM}$ ile bicibici ve $0.47 \pm 0.28$ GAE, mM ile acıgünek örneklerinin izlediği belirlenmiştir.

Vlase ve ark., (2014) dört farklı kurutulmuş Gallium türünün toplam fenolik madde miktarını araştırdıkları çalışmalarında Galium verum L. türünün toplam fenolik madde miktarının $2.6 \pm 0.12$ (GAE, $\mathrm{mM}$ ) olarak tespit ettiklerini belirtmişlerdir.

\subsection{Antimikrobiyal Aktivite}

Dört farklı yöresel bitki türünden elde edilen etanol ekstraklarının altı farklı gıda kaynaklı patojen üzerindeki antimikrobiyal aktiviteleri tablo 2 de gösterilmiştir.

Tablo 2. Bitki Ekstraklarının Bazı Gıda Patojenleri Üzerindeki Antimikrobiyal Aktiviteleri (mm Zon Çapı)

\begin{tabular}{lcccc}
\hline & $\begin{array}{c}\text { Acıgünek } \\
\text { (Taraxacum } \\
\text { officinale) }\end{array}$ & $\begin{array}{c}\text { Bicibici } \\
\text { (Polygonum cognatum) }\end{array}$ & $\begin{array}{c}\text { Siğır Kuyruğu } \\
\text { (Verbascum lasianthum) }\end{array}$ & $\begin{array}{c}\text { Ekşimen } \\
\text { (Galium verum) }\end{array}$ \\
\hline Esherichia coli & $12 \pm 0,05$ & $16 \pm 0,07$ & $9 \pm 0,01$ & $28 \pm 0,02$ \\
Listeria monocytogenes & $20 \pm 0,1$ & $18 \pm 0,03$ & $8 \pm 0,05$ & $26 \pm 0,00$ \\
Staphylococcus aureus & $14 \pm 0,12$ & $16 \pm 0,15$ & $8 \pm 0,01$ & $15 \pm 0,07$ \\
Enterococcus faecalis & $10 \pm 0,08$ & $10 \pm 0,05$ & $7 \pm 0,00$ & $18 \pm 0,05$ \\
Pseudomonas aeroginosa & $7 \pm 0,00$ & $7 \pm 0,00$ & $7 \pm 0,00$ & $9 \pm 0,00$ \\
Salmonella Typhi & $9 \pm 0,01$ & $14 \pm 0,01$ & $8 \pm 0,02$ & $22 \pm 0,1$ \\
\hline
\end{tabular}

Dört farklı bitki ekstraktı içerisinde en yüksek antimikrobiyal aktivitenin Ekşimen (Galium verum L.) tarafından en düşük aktivitenin ise; sı̆̆ır Kuyruğu (Verbascum lasianthum L.) gösterildiği tespit edilmiştir. Ekşimenin en yüksek antimikrobiyal aktiviteyi $28 \mathrm{~mm}$ zon çapı ile Escherichia coli üzerinde gösterdiği, bu bakteriyi $26 \mathrm{~mm}$ zon çapı ile Listeria monocytogenes ve $22 \mathrm{~mm}$ zon çapı ile Salmonella Typhi'nin izlediği belirlenmiştir.

Elde ettiğimiz antimikrobiyal aktivite değerleri, Clinical and Laboratory Standards Institute (CLSI) ve European Committee on Antimicrobial Susceptibility (EUCAST) tarafindan belilenen standart değerler (Tablo 3) ile kıyaslandığında; Esherichia coli, Listeria monocytogenes, Enterococcus faecalis ve Salmonella Typhi'nin ekşimen'e (Galium verum) duyarlı olduğu, Staphylococcus aureus'un orta duyarlı olduğu ve Pseudomonas aeroginosa'nın ise dirençli olduğu belirlenmiştir. Ayrıca araştırmamızda kullandığımız tüm patojenler ise, Sığır Kuyruğuna (Verbascum lasianthum) karşı duyarlı olduğu tespit edilmiştir.

Çalışmamızda elde ettiğimiz sonuçlara benzer şekilde Vlase ve ark., (2014), Gallium verum'um antimikrobiyal etkisinin Staphylococcus aureus üzerinde $11 \pm 0.05$, Listeria monocytogenes üzerinde $16 \pm 0.05$ ve Escherichia coli üzerinde $10 \pm 0.05 \mathrm{~mm}$ zon çapı olduğunu bildirmişlerdir.

Kahraman ve ark. (2011) çalışmalarında Staphylococcus aureus, Escherichia coli ve Pseudomonas aeroginosa'nın Verbascum lasianthum'a karşı dirençli olduğunu belirlemişlerdir. Araştırmacıları elde ettikleri sonuçlar araştırmamız bulgularına benzerlik göstermektedir.

\subsection{Minimum Inhibitory Concentration (MIC) ve Minimum Bactericidal Concentration (MBC)}

Afyonkarahisar ili ve çevresi kırsalında doğal olarak yetişen dört farklı bitkinin etanol ekstraklarının altı farklı gıda patojeni üzerindeki MIC değerleri Tablo 4 de gösterilmiştir.

En düşük MIC değerleri Ekşimen (Galium verum) tarafindan en yüksek MIC değerlerinin ise; sığır Kuyruğu tarafindan (Verbascum lasianthum) gösterildiği tespit edilmiştir. Ekşimenin en düşük MIC değerini $24 \mu \mathrm{g} / \mathrm{mL}$ ile Escherichia coli, Listeria monocytogenes ve Salmonella Typhi üzerinde göstermiştir. Buna karşın Sığır kuyruğunun (Verbascum lasianthum) MIC değerlerinin çalışmamızda kullandığımız tüm patojenler üzerinde $>1000 \mu \mathrm{g} / \mathrm{mL}$ olduğu belirlenmiştir. 
Tablo 3. CLSI and Eucast Clinical Microbiological Zone Diameter Standards (mm) (CLSI, 2015; EUCAST, 2018).

\begin{tabular}{|c|c|c|c|c|c|c|c|c|c|c|c|c|c|c|c|c|c|c|}
\hline \multirow[t]{2}{*}{ Antibiotics } & \multicolumn{3}{|c|}{ Esherichia coli } & \multicolumn{3}{|c|}{$\begin{array}{c}\text { Staphylococcus } \\
\text { aureus }\end{array}$} & \multicolumn{3}{|c|}{ Salmonella Typhi } & \multicolumn{3}{|c|}{$\begin{array}{c}\text { Enterococcus } \\
\text { faecalis }\end{array}$} & \multicolumn{3}{|c|}{$\begin{array}{c}\text { Listeria } \\
\text { monocytogenes }\end{array}$} & \multicolumn{3}{|c|}{$\begin{array}{c}\text { Pseudomonas } \\
\text { aeroginosa }\end{array}$} \\
\hline & $\mathbf{S}$ & I & $\mathbf{R}$ & $\mathbf{S}$ & I & $\mathbf{R}$ & $\mathbf{S}$ & I & $\mathbf{R}$ & $\mathbf{S}$ & $\mathbf{I}$ & $\mathbf{R}$ & $\mathbf{S}$ & $\mathbf{I}$ & $\mathbf{R}$ & $\mathbf{S}$ & I & $\mathbf{R}$ \\
\hline Ampicilin & $\geq 17$ & 14-16 & $\leq 13$ & NT & NT & NT & $\geq 17$ & $14-16$ & $\leq 13$ & $\geq 10$ & 9 & $\leq 8$ & $\geq 16$ & - & $\leq 16$ & NT & NT & NT \\
\hline Benzylpenicillin & $\geq 14$ & - & $\leq 14$ & $\geq 26$ & - & $\leq 26$ & $\geq 14$ & - & $\leq 14$ & NT & NT & NT & $\geq 13$ & - & $\leq 13$ & NT & NT & NT \\
\hline Amoxicillin-clavulanic acid & $\geq 18$ & $14-17$ & $\leq 13$ & NT & NT & NT & $\geq 18$ & $14-17$ & $\leq 13$ & NT & NT & NT & NT & NT & NT & NT & NT & NT \\
\hline Gentamicin GN10 & $\geq 15$ & $13-14$ & $\leq 12$ & $\geq 15$ & $13-14$ & $\leq 12$ & $\geq 15$ & $13-14$ & $\leq 12$ & NT & NT & NT & NT & NT & NT & NT & NT & NT \\
\hline Penicilin & NT & NT & NT & $\geq 29$ & - & $\leq 28$ & NT & NT & NT & NT & NT & NT & NT & NT & NT & NT & NT & NT \\
\hline Netilmicin & $\geq 15$ & 13-14 & $\leq 12$ & $\geq 18$ & - & $\leq 18$ & $\geq 15$ & $13-14$ & $\leq 12$ & NT & NT & NT & NT & NT & NT & NT & NT & NT \\
\hline Erythromycin & NT & NT & NT & $\geq 23$ & $14-22$ & $\leq 13$ & NT & NT & NT & NT & NT & NT & $\geq 25$ & - & $\leq 25$ & NT & NT & NT \\
\hline Streptomycin & $\geq 15$ & $12-14$ & $\leq 11$ & $\mathrm{NT}$ & NT & NT & $\geq 15$ & $12-14$ & $\leq 11$ & NT & NT & NT & NT & NT & NT & NT & NT & NT \\
\hline Chloramphenicol & $\geq 18$ & $13-17$ & $\leq 12$ & $\geq 18$ & $13-17$ & $\leq 12$ & $\geq 18$ & $13-17$ & $\leq 12$ & NT & NT & NT & NT & NT & NT & NT & NT & NT \\
\hline Sulfonamides & $\geq 17$ & $13-16$ & $\leq 12$ & $\geq 17$ & $13-16$ & $\leq 12$ & $\geq 17$ & $13-16$ & $\leq 12$ & NT & NT & NT & NT & NT & NT & NT & NT & NT \\
\hline Kanamycin & $\geq 18$ & $14-17$ & $\leq 13$ & $\geq 18$ & $14-17$ & $\leq 12$ & $\geq 18$ & $14-17$ & $\leq 13$ & NT & NT & NT & NT & NT & NT & NT & NT & NT \\
\hline Tetracycline & NT & NT & NT & $\geq 19$ & $15-18$ & $\leq 14$ & NT & NT & NT & NT & NT & NT & NT & NT & NT & NT & NT & NT \\
\hline Clindamycin & NT & NT & NT & $\geq 21$ & $15-20$ & $\leq 14$ & NT & NT & NT & NT & NT & NT & NT & NT & NT & NT & NT & NT \\
\hline Fusidic Acid & NT & NT & NT & $\geq 24$ & - & $\leq 44$ & NT & NT & NT & NT & NT & NT & NT & NT & NT & NT & NT & NT \\
\hline Penicilin & NT & NT & NT & $\geq 29$ & - & $\leq 28$ & NT & NT & NT & NT & NT & NT & NT & NT & NT & NT & NT & NT \\
\hline Piperacilin & $\geq 20$ & 16-19 & $\leq 17$ & NT & NT & NT & NT & NT & NT & NT & NT & NT & NT & NT & NT & $\geq 18$ & - & $\leq 18$ \\
\hline Ticarcilin & $\geq 23$ & $21-22$ & $\leq 20$ & NT & NT & NT & NT & NT & NT & NT & NT & NT & NT & NT & NT & $\geq 18$ & - & $\leq 18$ \\
\hline
\end{tabular}

NT: Çalıșma yok, S: Duyarlı, I:Orta duyarlı, R: dirençli 
Tablo 4. Bitki Ekstraklarının MIC Dĕgerleri $(\mu \mathrm{g} / \mathrm{mL})$.

\begin{tabular}{|c|c|c|c|c|c|c|c|c|}
\hline \multirow{3}{*}{ Bakteri } & \multicolumn{8}{|c|}{ MIC $(\mu \mathrm{g} / \mathrm{mL})$ ve MBC $(\mu \mathrm{g} / \mathrm{mL})$ Değerleri } \\
\hline & \multicolumn{2}{|c|}{$\begin{array}{c}\text { Acıgünek } \\
\text { (Taraxacum } \\
\text { officinale) } \\
\end{array}$} & \multicolumn{2}{|c|}{$\begin{array}{c}\text { Bicibici } \\
\text { (Polygonum } \\
\text { cognatum) }\end{array}$} & \multicolumn{2}{|c|}{$\begin{array}{l}\text { Sığır Kuyruğu } \\
\text { (Verbascum } \\
\text { lasianthum }\end{array}$} & \multicolumn{2}{|c|}{$\begin{array}{c}\text { Ekşimen } \\
\text { (Galium verum) }\end{array}$} \\
\hline & MIC & MBC & MIC & MBC & MIC & MBC & MIC & MBC \\
\hline Esherichia coli & 192 & 384 & 192 & 384 & $>1000$ & $>1000$ & 24 & 48 \\
\hline Listeria monocytogenes & 48 & 96 & 96 & 192 & $>1000$ & $>1000$ & 24 & 48 \\
\hline Staphylococcus aureus & 192 & 384 & 384 & 768 & $>1000$ & $>1000$ & 384 & 768 \\
\hline Enterococcus faecalis & 384 & 768 & 384 & 768 & $>1000$ & $>1000$ & 48 & 192 \\
\hline Pseudomonas aeroginosa & $>1000$ & $>1000$ & $>1000$ & $>1000$ & $>1000$ & $>1000$ & $>1000$ & $>1000$ \\
\hline Salmonella Typhi & 768 & $>1000$ & 192 & 384 & $>1000$ & $>1000$ & 24 & 48 \\
\hline
\end{tabular}

Sonuçlarımız; EUCAST tarafından belilenen standart MIC değerleri (Tablo 5) ile kıyaslandığında Esherichia coli, Listeria monocytogenes ve Salmonella Typhi'nin ekşimen'e (Galium verum) duyarlı olduğu, Enterococcus faecalis, Staphylococcus aureus ve Pseudomonas aeroginosa'nın ise dirençli olduğu belirlenmiştir.

Tablo 5. Eucast Clinical MIC Breakpoint Tables (mg/L) (EUCAST, 2018).

\begin{tabular}{|c|c|c|c|c|c|c|c|c|c|c|c|c|}
\hline \multirow[t]{2}{*}{ Antibiotics } & \multicolumn{2}{|c|}{$\begin{array}{c}\text { Esherichia } \\
\text { coli }\end{array}$} & \multicolumn{2}{|c|}{$\begin{array}{c}\text { Staphylococcus } \\
\text { aureus }\end{array}$} & \multicolumn{2}{|c|}{$\begin{array}{c}\text { Salmonella } \\
\text { Typhi }\end{array}$} & \multicolumn{2}{|c|}{$\begin{array}{c}\text { Enterococcus } \\
\text { faecalis }\end{array}$} & \multicolumn{2}{|c|}{$\begin{array}{c}\text { Listeria } \\
\text { monocytogenes }\end{array}$} & \multicolumn{2}{|c|}{$\begin{array}{c}\text { Pseudomonas } \\
\text { aeroginosa }\end{array}$} \\
\hline & $\mathbf{S} \leq$ & R> & $\mathbf{S} \leq$ & $\mathbf{R}>$ & $\mathbf{S} \leq$ & $\mathbf{R}>$ & $\mathbf{S} \leq$ & $\mathbf{R}>$ & $\mathbf{S} \leq$ & $\mathbf{R}>$ & $\mathbf{S} \leq$ & $\mathbf{R}>$ \\
\hline Benzylpenicillin & NT & NT & 0,125 & 0,125 & NT & NT & NT & NT & 1 & 1 & NT & NT \\
\hline Ampicilin & 8 & 8 & NT & NT & 8 & 8 & 4 & 8 & 1 & 1 & NT & NT \\
\hline Gentamicin & 2 & 4 & 1 & 1 & 2 & 4 & NT & NT & NT & NT & NT & NT \\
\hline Netilmicin, & 2 & 4 & 1 & 1 & 2 & 4 & NT & NT & NT & NT & NT & NT \\
\hline Erythromycin & NT & NT & 1 & 2 & NT & NT & NT & NT & 1 & 1 & NT & NT \\
\hline Clindamycin & NT & NT & 0,25 & 0,5 & NT & NT & NT & NT & NT & NT & NT & NT \\
\hline Fusidic acid & NT & NT & 1 & 1 & NT & NT & NT & NT & NT & NT & NT & NT \\
\hline Chloramphenicol & 8 & 8 & 8 & 8 & 8 & 8 & NT & NT & NT & NT & NT & NT \\
\hline Tetracycline & NT & NT & 1 & 2 & NT & NT & NT & NT & NT & NT & NT & NT \\
\hline Cefalexin & 16 & 16 & NT & NT & 16 & 16 & NT & NT & NT & NT & NT & NT \\
\hline Amoxicillin & 8 & 8 & NT & NT & 8 & 8 & 4 & 8 & NT & NT & NT & NT \\
\hline Piperacilin & 8 & 16 & NT & NT & 8 & 16 & 4 & 8 & NT & NT & 16 & 16 \\
\hline Ticarcilin & 8 & 16 & NT & NT & 8 & 16 & NT & NT & NT & NT & 16 & 16 \\
\hline
\end{tabular}

NT: Çalışma yok, S: Duyarlı, R: dirençli

Benzer şekilde en düşük MBC değerlerinin Ekşimen (Galium verum L.) tarafından gösterildiği belirlenmiştir. Sı̆̆ır kuyruğu (Verbascum lasianthum L.) tarafindan gösterilen MBC değerlerinin ise, çalışmamızda kullandığımız tüm patojenlere karşı >1000 olduğu tespit edilmişstir.

Vasilevna ve ark. (2016) Ekşimenin (Galium verum L.) MIC değerlerini Staphylococcus aureus üzerinde $62.5 \mu \mathrm{g} / \mathrm{mL}$, Escherichia coli üzerinde $250 \mu \mathrm{g} / \mathrm{mL}$ ve Pseudomonas aeroginosa üzerinde ise $250 \mu \mathrm{g} / \mathrm{mL}$ olarak tespit ettiklerini bildirmişlerdir. Aynı araştırmacılar Galium verum'un MBC değerlerini, Staphylococcus aureus üzerinde $125 \mu \mathrm{g} / \mathrm{mL}$, Escherichia coli üzerinde $500 \mu \mathrm{g} / \mathrm{mL}$ ve Pseudomonas aeroginosa üzerinde ise $250 \mu \mathrm{g} / \mathrm{mL}$ olarak bildirmişlerdir.

Şener ve Dülger (2009) Verbascum sinuatum'un MIC ve MBC değerlerini Enterococcus faecalis için 4 ve $8 \mu \mathrm{g} / \mathrm{mL}$, Escherichia coli için 500 ve $1000 \mu \mathrm{g} / \mathrm{mL}$ ve Pseudomonas aeruginosa için 250 ve $500 \mu \mathrm{g} / \mathrm{mL}$, olarak tespit ettiklerini belirtmişlerdir. Araştırmacıların elde ettiği sonuçlar sonuçlarımız ile büyük ölçüde benzerlik göstermesine rağmen bazı farklılıklar bulunmaktadır. Aradaki bu farklılıkların; bitkilerdeki tür, çalışmalarda kullanılan suş ve uygulanan yöntem farklılıklarından kaynaklandığı düşünülmektedir.

Gallium verum L.'un etanol ekstraktının antimikrobiyal etkisinin, bitkinin bileşiminde bulunan kaempferol, 1soquersitrin, quarcetin ve quersitrinden kaynaklandığı (Valle ve ark., 2016; Taiwo ve Ibenghu, 2014; Tatsimo ve ark., 2012) bildirilmiştir. Ayrıca rutinin kendi başına herhangi bir antimikrobiyal aktivite göstermemesine karşın, rutin varlığında diğer bileşenlerin aktiviteleri artırdığı araştırmacılar tarafından ortaya konulmuştur (Arima ve ark., 2002). 


\section{Sonuç}

$\mathrm{Bu}$ araştırmada Afyonkarahisar bölgesinde yetişen ve bölgede yaşayan halk tarafindan gıda amaçlı olarak tüketilen, yabani bitkilerden bazılarının antioksidan ve antimikrobiyal etkileri araştırmıştır. Çalışmada kullanılan bitkilerin özellikle zengin antioksidan özelliklere sahip oldukları belirlenmiştir. Benzer şekilde, Sığır kuyruğu hariç diğer bitkilerin (özellikle ekşimen) çalışmamızda kullandığımız altı patojenin beşine karşı antimikrobiyal etki gösterdiği tespit edilmiştir.

Yöre halkı tarafindan çok uzun zamandan beri tüketilen bu bitkiler ile ilgili daha fazla araştırmanın yapılması sonucunda bu bitkilerin; günlük diyetimiz içerisine alınarak, diğer bölgelerde de tüketilebilmesinin gerçekleştirilmesi, sadece doğada yabani ortamlarda ve belli bölgelerde değil, kültüre alınarak tüm bölgelerde ve daha geniş çaplı olarak yetiştirilmesinin sağlanmasının gerekliliği düşünülmektedir.

Ayrıca bugün gıda sanayisinde kullanılan pek çok kimyasal kaynaklı koruyucuya alternatif olarak bu bitkiler ve bu bitkilerden elde edilecek ürünlerin kullanılması ile, hem daha doğal gıdaların elde edilmesi sağlanmış olunacak ve hem de tüketicilerin akıllarında oluşan pek çok sorunun da önüne geçileceği kaçınılmazdır. 


\section{Kaynakça}

Akçiçek, E., \& Vural, M. (2007). Kumalar dağı (Afyonkarahisar)' nın endemik ve nadir bitkileri. BAÜ FBE Dergisi, 9(2), 78-86.

Anonim. (2010). Afyonkarahisar, Afyonkarahisar Belediyesi.

Arima, H., Ashida, H., \& Danno, G. (2002). Rutin-enhanced antibacterial activities of flavonoids against Bacillus cereus and Salmonella Enteritidis. Biosci Biotechnol Biochem, 66(5), 1009-1114. http://dx.doi.org/10.1271/bbb.66.1009

Başer, K.H.C. (2015). Sığırkuyruğu (Verbascum spp.) Bă̆ Bahçe, 61, 22-23.

Bokhari, J., Khan, M.R., Shabbir, M., Rashid, U., Jan, S., \& Zai, J.A. (2013). Evaluation of diverse antioxidant activities of Galium aparine. Spectrochimica Acta Part A: Molecular and Biomolecular Spectroscopy, 102, 24-29.

By Aamer, A.A., Abdul-Hafeez, M.M., \& Sayed, S.M. (2015). Minimum inhibitory and bactericidal concentrations (MIC \& MBC) of honey and bee propolis against multidrug resistant (MDR) Staphylococcus Spp. isolated from bovine clinical mastitis. Global Journal of Science Frontier Research: D Agriculture and Veterinary, 15(2), Version 1.0.

Chikezie, I.O. (2017). Determination of minimum inhibitory concentration (MIC) and minimum bactericidal concentration (MBC) using a novel dilution tube method. African Journal of Microbiology Research, 11(23), 977-980.https://doi.org/ 10.5897/AJMR2017.8545

Chu, S.C., \& Chen, C. (2006). Effects of origins and fermentation time on the antioxidant activities of Kombucha. Food Chemistry, 98, 502-507.https://doi.org/ 10.1016/j.foodchem.2005.05.080

CLSI. (2015). Clinical and Laboratory Standards Institute, Zone diameter and minimal inhibitory concentration (MIC) Standards.

Cruz-Gálvez, A.M., Castro-Rosas, J., Rodríguez-Marín, M.L., Cadena-Ramírez, A., Tellez-Jurado, A. TovarJiménez, X., ve ark. (2018). Antimicrobial activity and physicochemical characterization of a potato starch-based film containing acetonic and methanolic extracts of Hibiscus sabdariffa for use in sausage. LWT-Food Science and Technology, 93, 300-305. https://doi.org/10.1016/j.lwt.2018.02.064

Da-Costa-Rocha, I., Bonnlaender, B., Sievers, H., Pischel, I., \& Heinrich, M. (2014). Hibiscus sabdariffa L. A phytochemical and pharmacological review. Food Chemistry, 165, 424-443.https://doi.org/ 10.1016/j.foodchem.2014.05.00

Dhiman, A., Nanda, A., Ahmad, S., \& Narasimhan, B. (2011). In vitro antimicrobial activity of methanolic leaf extract of Psidium guajava L. J Pharm Bioallied Sci, 3(2), 226-229. http://dx.doi.org/10.4103/09757406.80776

El-Mahmood, M.A. (2009). Antibacterial efficacy of stem bark extracts of Mangifera indica against some bacteria associated with respiratory tract infections. Sci Res Essays, 4(10), 1031-1037.

Eucast. (2018). European Committee on Antimicrobial Susceptibility Testing. http://www.eucast.org/fileadmin/src/media/PDFs/EUCAST_files/Breakpoint_tables/v_8.0_Breakpoint_T ables.pdf

Kahraman, Ç., Ekizoğlu, M., Kart, D., Akdemir, Z.Ş., \& Tatlı, I.I. (2011). Antimicrobial activity of some Verbascum species growing in Turkey. FABAD J. Pharm. Sci, 36, 11-15.

Şener, A., \& Dülger, B. (2009). Antimicrobial activity of the leaves of Verbascum sinuatum L. on microorganisms isolated from urinary tract infection. African Journal of Microbiology Research, 3(11), $778-781$

Taiwo, B.J., \& Igbeneghu, O.A. (2014). Antioxidant and Antibacterial Activities of Flavonoid Glycosides from Ficus Exasperata Vahl-Holl (Moraceae) Leaves. Afr J Tradit Complement Altern Med, 11(3), 97-101. http://dx.doi.org/10.4314/ajtcam.v11i3.14 
Tatsimo, S.J., Tamokou, J.D., Havyarimana, L., Csupor, D., Forgo, P., Hohmann, ve ark. (2012). Antimicrobial and antioxidant activity of kaempferol rhamnoside derivatives from Bryophyllum pinnatum. BMC Res Notes, 20, 105-158. https://doi.org/10.1186/1756-0500-5-158.

Valle, P., Garcia-Armesto, R.G., Ariaga, D., Gonzalez-Donquiles, C., Rodriguez-Fernandez, P., \& Rua, J. (2016). Antimicrobial activity of kaempferol and resveratrol in binary combinations with parabens or propyl gallate against Enterococcus faecalis. Food Control, 61, 213-220. https://doi.org/10.1016/j.foodcont.2015.10.001

Vasilevna, I.T., Volodymyrivna1, G.O., Leonidivna, T. E., Aleksandrovna, K.I., \& Mihaylovna1, K.A. (2016). Antimicrobial Activity of the Genus Galium L. Pharmacogn. Commn, 6(1), 42-47. http://dx.doi.org/10.5530/pc.2016.1.8

Vlase, L., Mocan, A., Hanganu, D., Benedec, D., Gheldiu, A., \& Crışan, G. (2014). Comparative study of polyphenolic content, antioxidant and antimicrobial activity of four Galium Species (Rubiaceae) digest. Journal of Nanomaterials and Biostructures, 9(3),1085-1094.

Wang, K., Zhang, Y.J., \& Yang, C.H. (2005). Antioxidant phenolic compounds from rhizomes of Polygonum paleaceum. J. Etnopharmacol, 96, 483-487.

You, Y., Yoo, S., Yoon, H. G., Park, J., Lee, H. Y., Kim, S., Oh, K. T., ve ark. (2010). In vitro and in vivo hepatoprotective effects of the aqueous extract from Taraxacum officinale (dandelion) root against alcohol-induced oxidative stress. Food and Chemical Toxicology, 48(6), 1632-1637. https://doi.org/ 10.1016/j.fct.2010.03.037

Yücel, E. \& Tunay, M. (2002). Nazilli (Aydın) ve yöresinde gıda olarak kullanılan yabancı otlar. Türkiye Herboloji Dergisi, 5(2), 10-17.

Yücel, E. (2012). Türkiye’nin Çayır, Mera ve Ormanlarının Zehirli Bitkileri. Ulus/ Ankara: Arkadaş Basım.

Yücel, E., Yücel Şengün, İ., \& Çoban, Z. (2012). The wild plants consumed as a food in Afyonkarahisar/Turkey and consumption forms of these plants. Biological Diversity and Conservation, 5(2), 95-105. 